\title{
Um Passeio Institucionalista pela Assembléia Paulista
}

\section{Roberta Clemente ${ }^{1}$}

RESUMO: Este trabalho utiliza duas correntes institucionalistas, o institucionalismo da escolha racional e o institucionalismo histórico para analisar o mesmo objeto, a participação da Assembléia Legislativa paulista no sistema político estadual. Inicialmente, são analisados Constituição estadual e Regimento Interno, com o intuito de identificar eventuais atores com efetivo poder de veto, com foco nos poderes legislativos do Governador e na distribuição dos recursos parlamentares internos ao legislativo. Em seguida, serão buscadas as raízes históricas da centralização de poderes encontrada.

PALAVRAS-CHAVE: teoria institucional, legislativo, São Paulo (estado).

ABSTRACT: This paper addresses legislature participation in the state political system, through two institutionalist approaches: Rational Choice and Historical Institutionalism. Initially, it analyses the state Constitution and the legislature's internal rules in order to identify potential veto players, focusing primarily on the governor's legislative prerogatives and the distribution of parliamentary resources amongst members of the legislature. Finally, there's a search for the historical origins of the centralization of power encountered in the legislature.

KEYWORDS: institutionalism, legislature, state, Brazil, São Paulo.

\footnotetext{
${ }^{1}$ Doutoranda em Administração Pública na Escola de Administração de Empresas de São Paulo - Fundação Getúlio Vargas. Agente Técnica Legislativo da Assembléia de São Paulo. Contatos: robertaclemente@gvmail.br.Rua da Consolação 3638 apt.64c cep 01416000 São Paulo.
} 
Este trabalho objetiva fazer um exercício usando como objeto a participação do Poder Legislativo estadual paulista no sistema político paulista usando elementos de duas correntes institucionalistas: a Escolha Racional e o Institucionalismo Histórico. Em um primeiro momento, será usado o modelo proposto por Haggard e McCubbins no livro Presidents, Parliaments and Policy, que estuda o efeito das instituições sobre as políticas públicas no sistema político nacional, adaptando-o a outro nível de governo, o estadual. Em seguida, utilizando o Institucionalismo Histórico, procuraremos verificar como estas instituições foram construídas. O estado escolhido para esse teste, é o Estado de São Paulo, que possui autonomia política, administrativa e orçamentária.

São Paulo adota regime presidencialista unicameral e o distrito eleitoral do Chefe do Poder Executivo é o mesmo dos integrantes do Poder Legislativo, e as eleições são “casadas”, ou seja, a renovação do Executivo e do Legislativo ocorre ao mesmo tempo. No nível nacional no Brasil, o Legislativo é bicameral e o distrito eleitoral dos parlamentares são os estados, enquanto que o do Presidente é o país.

No modelo proposto por Haggard e McCubbins, as variáveis independentes são:

1 Os Poderes do Chefe do Executivo

1.1 Quais os poderes específicos do governador sobre a elaboração de políticas públicas? O Chefe do Poder Executivo possui poderes reativos, como a autoridade para vetar ou retardar legislação? O Chefe do Executivo tem poder de veto total ou parcial?

1.2 Quais os poderes proativos específicos do Chefe do Executivo? Em quais áreas o governador tem autoridade para tomar medidas unilaterais - ações não sujeitas ao controle legislativo e que independem de sua aprovação? O Chefe do Executivo tem poder de decreto? Qual a autoridade do Chefe do Executivo na elaboração do orçamento? Pode o projeto do Executivo se tornar o resultado em caso de impasse legislativo.

1.3 No que se refere à separação de propósito dentro do Executivo, quanto do processo decisório é delegado ao secretariado? Existem agências independentes ou órgãos consultivos além do secretariado dos quais o Governador depende? 
2 As instituições Legislativas

2.1 O Legislativo é unicameral ou bicameral? Alguma das Câmaras (ou ambas) possui poder de veto sobre políticas públicas propostas? Qual a parcela dos legisladores necessária para exercer este poder? Alguma das Casas (ou ambas) tem poder de agenda?

2.2 No que se refere a separação de propósito dentro do Legislativo, se bicameral, os eleitorados são congruentes ou incongruentes?

Sugerimos acrescentar a seguinte pergunta:

2.3 No que se refere à organização interna do Legislativo: quem tem poder de veto efetivo?

3 Federalismo

3.1 O governo nacional determina a liderança das unidades de governo de nível mais baixo (estadual ou municipal), ou esta liderança é selecionada localmente?

3.2 As unidades locais têm poderes tributários e orçamentários independente do Governo nacional, ou necessitam de permissão explícita?

3.3 As autoridades locais têm poder de controlar ou resistir a iniciativas políticas públicas iniciadas pelo Governo Federal? Se sim, por quais meios e em qual extensão podem resistir?

4 Regras eleitorais e separação de propósito

4.1 Como os parlamentares são eleitos e reeleitos? O sistema eleitoral legislativo é organizado de maneira proporcional ou plural? Há concorrência intrapartidária? Quantos parlamentares são eleitos por distrito? Quantos distritos eleitorais existem? Como são definidos?

4.2 Quem tem autoridade e responsabilidade para definir as nomeações partidárias? As leis eleitorais governam os partidos políticos? Quão fácil é para um candidato ser incluído na cédula?

4.3 Qual a freqüência das eleições? Ocorrem simultaneamente para o Executivo e Legislativo? 
4.4 São determinados os mandatos do Governador? Pode ele ser indicado novamente ou reeleito?

Tendo em vista que pretendemos olhar para um sistema político sub-nacional, o do Estado de São Paulo, acreditamos que devemos começar tentando responder às questões referentes ao pacto federativo.

O Federalismo é, per se, um mecanismo consociativista (para Haggard e McCubbins mais resoluto em detrimento de sua decisibilidade), concebido exatamente para evitar a tirania da maioria e garantir a unidade em meio à diversidade, uma vez que várias instâncias e organismos de poder independentes e concorrentes entre si, poderiam evitar que o Estado crescesse sobremaneira e oprimisse as minorias.

No federalismo, algumas questões cabem exclusivamente a algumas unidades locais cantões, estados, províncias - e estão constitucionalmente além da autoridade do governo central e algumas outras questões estão constitucionalmente fora do alcance das unidades sub-nacionais (STEPAN 1997). Stepan afirma que somente um sistema que é uma democracia pode construir um sistema constitucional, legislativo e judicial relativamente autônomo para cumprir os requisitos dahlianos de federação que são: dentro do Estado deve haver algumas sub-unidades cujo eleitorado seja exclusivamente formado por cidadãos desta sub-unidade, cuja área legal e de autonomia para implementação de políticas, bem como de soberania seja constitucionalmente garantida; deve haver, ainda, uma unidade política central que abranja todo o país, que contenha um Legislativo eleito pela população de todo o território, cuja área de abrangência legal e de elaboração de políticas seja constitucionalmente garantidas a este corpo central.

O Federalismo brasileiro é uma instituição que sofreu diversas modificações de acordo com o contexto político do país: na Primeira República (1889 - 1930), o centro era fraco em relação aos estados formados por oligarquias regionais e provinciais já poderosas na época do Império (OLIVEIRA 1995). A partir da Revolução de 1930, a União vai se fortalecendo em detrimento dos estados, até 1946, quando há uma descentralização, ainda que insuficiente para reverter o processo anterior. De 1964 a 1978, ocorre um processo de concentração de poder nas mãos da União em detrimento dos estados que ficam praticamente sem autonomia. A partir de 1978, o processo de redemocratização, que teve 
início a partir dos estados e municípios, confunde-se com a luta pela descentralização fiscal e administrativa, o que foi conquistado com a promulgação da Constituição de 1988. Os municípios adquiriram uma autonomia sem precedentes, e aos estados coube uma competência residual, que pode ser interpretada de duas maneiras: tornou-se o nível de governo com maiores atribuições, uma vez que lhe compete tudo o que não lhe for expressamente vedado no texto constitucional, ou como um nível de poder sem atribuição específica.

De acordo com o texto Constitucional de 1988, a União não pode intervir nos Estados nem no Distrito Federal, exceto para: manter a integridade nacional; repelir invasão estrangeira ou de uma unidade da Federação em outra; pôr termo a grave comprometimento da ordem pública; garantir o livre exercício de qualquer dos Poderes nas unidades da Federação; reorganizar as finanças da unidade da Federação que suspender o pagamento da dívida fundada por mais de dois anos consecutivos, salvo motivo de força maior e deixar de entregar aos Municípios receitas tributárias fixadas na Constituição dentro dos prazos estabelecidos em lei; prover a execução de lei federal, ordem ou decisão judicial e assegurar a observância dos seguintes princípios constitucionais: forma republicana, sistema representativo e regime democrático; direitos da pessoa humana; autonomia municipal e prestação de contas da administração pública, direta e indireta.

Além disso, os Estados têm competência para instituir impostos sobre transmissão causa mortis e doação, de quaisquer bens ou direitos (cujas alíquotas máximas são fixadas pelo Senado Federal); operações relativas à circulação de mercadorias e sobre prestações de serviços de transporte interestadual e intermunicipal e de comunicação (ICMS, dos quais 25\% pertencem aos municípios) e propriedade de veículos automotores (IPVA, dos quais 50\% pertencem ao município onde o veículo for licenciado).

Quanto à competência legislativa, os estados têm competência concorrente com a União, cabendo à União estabelecer normas gerais para legislar sobre direito tributário, urbanístico, econômico, financeiro e penitenciário; bem como sobre orçamento; juntas comerciais; custas dos serviços forenses; criação, funcionamento e processo do juizado de pequenas causas; organização, garantias, direitos e deveres das polícias civis; produção e consumo; florestas, caça, pesca, fauna, conservação da natureza, defesa do solo e dos recursos naturais, proteção do meio ambiente e controle da poluição; proteção ao 
patrimônio histórico, cultural, artístico, turístico e paisagístico; responsabilidade por dano ao meio ambiente, ao consumidor, a bens e direitos de valor artístico, estético, histórico, turístico e paisagístico; educação, cultura, ensino e desporto; procedimentos em matéria processual; previdência social, proteção e defesa da saúde; assistência jurídica e defensoria pública; proteção e integração social das pessoas portadoras de deficiência e proteção à infância e à juventude.

No que se refere ao preenchimento de cargos eletivos, a União tem competência privativa para legislar sobre direito eleitoral. A Constituição federal determina que a cadeira do chefe do Executivo nos três níveis de governo do Brasil (federal, estadual e municipal) é preenchida através do sistema majoritário, bem como a distribuição de cadeiras no Senado Federal. O preenchimento das cadeiras da Câmara dos Deputados, das Assembléias Legislativas e das Câmaras de Vereadores, é feito de maneira proporcional.

O número de cadeiras a serem preenchidas na Câmara Federal é determinado pela população do estado, que é o distrito eleitoral dos deputados federais, sendo o mínimo de 8 deputados e o máximo de 70. O número de cadeiras nas Assembléias Legislativas é determinado em função do número de deputados federais referentes a cada estado:

“Art. 27 O número de deputados à Assembléia Legislativa corresponderá ao triplo da representação do Estado na Câmara dos Deputados e, atingido o número de trinta e seis, será acrescido de tantos quantos forem os deputados Federais acima de doze”.

No Brasil tanto o Executivo quanto o Legislativo estaduais e municipais são eleitos localmente, tendo como distrito eleitoral a totalidade da unidade administrativa. Ocorrem a cada quatro anos, e são simultâneas para governador e deputados e para vereador e prefeito (as eleições municipais ocorrem na metade do mandato dos governadores e deputados estaduais).

O Estado de São Paulo tem 70 deputados federais e, portanto, 94 deputados estaduais. Cada partido ou coligação pode lançar até dois candidatos por vaga a ser preenchida, o eleitor escolhe apenas um candidato ou uma legenda partidária, e o número de vagas que corresponderá a cada partido será dado pela somatória dos votos que cada candidato do partido tiver recebido, mais os votos na legenda, dividido pelo total de votos válidos. O preenchimento das vagas do partido será feito de acordo com a ordem de votação dos 
candidatos, o que significa que, se um partido ou coligação tiver conquistado dez cadeiras, estas serão preenchidas pelos dez primeiros candidatos mais votados do partido ou coligação, o que configura sistema eleitoral de lista aberta.

A magnitude do distrito poderia ensejar os parlamentares a pensar, assim como o Chefe do Executivo no Estado como um todo e não em políticas localizadas. A magnitude do distrito é a totalidade do estado, o que significa que o número de candidatos por distrito poderá ser igual ao dobro do número de partidos ou coligações multiplicado pelo número total de cadeiras. Se o número de partidos for igual a 30, nenhum se coligar e todos lançarem o número máximo de candidatos, em um pleito pode haver sessenta candidatos por vaga e um total de 5640 candidatos por distrito.

Em defesa deste sistema afirma-se que a proporcionalidade reforça a igualdade perante a lei, no que se refere a partidos e a cidadãos, no processo de transformação de votos em cadeira. Caso o sistema fosse majoritário, apenas os eleitores dos candidatos mais votados seriam representados (LIMA JÚNIOR 1997). Os críticos a este sistema afirmam que causa distorções, porque o eleitor perde o controle de seu voto que pode vir a beneficiar um candidato do mesmo partido que o eleitor não gostaria de eleger. Argumentam que pode fazer com que um candidato que tenha recebido 70 mil votos não se eleja, enquanto um que tenha 15 mil seja eleito, e os partidos menores seriam penalizados. Afirmam, ainda, que estimula os caciques partidários a “caçarem” candidatos “puxadores de votos”, muitas vezes sem qualquer vínculo programático com o partido, e, como se não bastasse, torna concorrentes ferrenhos os candidatos do mesmo partido, o que faz com que as campanhas sejam centradas na pessoa do candidato e não no programa partidário.

Quem define a cédula partidária é a convenção do partido, de acordo com regras próprias de cada partido. O partido não é responsável pelos seus candidatos ou representantes eleitos, o que facilita a entrada na cédula de qualquer candidato que mostre bom potencial de "puxador de voto".

O destino eleitoral dos candidatos independe do partido, o que, segundo Haggard e McCubbins (2001) geraria mais jogadores com poder de veto em potencial e tornaria o sistema mais resoluto e menos decisório. Entretanto, como as eleições são simultâneas às eleições para o cargo de governador, favorece a ligação entre os destinos eleitorais dos candidatos ao legislativo e ao executivo. Além disso, o fato de a eleição para o cargo a 
governador ser feita em dois turnos, pode ser favorecida a formação de coalizões para a formação de maiorias. A simultaneidade das eleições privilegiaria a decisibilidade do sistema, em detrimento de sua resolutividade.

No que diz respeito aos poderes reativos do Chefe do Executivo, no estado de São Paulo, o Governador tem iniciativa exclusiva de leis que disponham sobre: criação e extinção de cargos, funções ou empregos públicos na administração direta e autárquica, bem como a fixação da respectiva remuneração; criação das Secretarias de Estado; organização da Procuradoria Geral do Estado e da Defensoria Pública do Estado, observadas as normas gerais da União; servidores públicos do Estado, seu regime jurídico, provimento de cargos, estabilidade e aposentadoria de civis, reforma e transferência de militares para a inatividade; fixação ou alteração do efetivo da Polícia Militar; criação, alteração ou supressão de cartórios notariais e de registros públicos; matéria orçamentária; financeira.

O veto pode ser total ou parcial, desde que abranja, por inteiro, o artigo, o parágrafo, o inciso, o item ou alínea. A Assembléia Legislativa deve deliberar sobre a matéria vetada, em único turno de votação e discussão, no prazo de trinta dias de seu recebimento, considerando-se aprovada quando obtiver o voto favorável da maioria absoluta de seus membros (48 deputados votando contrariamente ao veto se houver 48 deputados na sessão e um votar a favor do veto e 47 contrariamente, o veto será mantido). Se o veto não for deliberado em trinta dias, é incluído na ordem do dia da sessão imediata, até sua votação final.

O Governador pode solicitar que os projetos de sua iniciativa tramitem em regime de urgência. Se a Assembléia Legislativa não deliberar em até quarenta e cinco dias, o projeto é incluído na ordem do dia até que ocorra a sua votação. Tanto o veto quanto o pedido de urgência dão ao governador o poder de ditar a pauta e o ritmo dos trabalhos da Assembléia. Compete privativamente ao Governador representar o Estado nas suas relações jurídicas, políticas e administrativas; exercer, com o auxílio dos Secretários de Estado (que são auxiliares diretos e da confiança do Governador, por ele nomeados e exonerados livremente, desde que sejam brasileiros maiores de vinte e um anos e no exercício dos direitos políticos), a direção superior da administração estadual; nomear e exonerar os dirigentes de autarquias, indicar diretores de sociedade de economia mista e empresas 
públicas; decretar e fazer executar intervenção nos Municípios, na forma da Constituição Federal.

O governador necessita de autorização da Assembléia para subscrever ou adquirir ações, realizar ou aumentar capital, desde que haja recursos hábeis, de sociedade de economia mista ou de empresa pública, bem como dispor, a qualquer título, no todo ou em parte, de ações ou capital que tenha subscrito, adquirido, realizado ou aumentado, enviar à Assembléia Legislativa projetos de lei relativos ao plano plurianual, diretrizes orçamentárias, orçamento anual, dívida pública e operações de crédito; projeto de lei sobre o regime de concessão ou permissão de serviços públicos; alienação de bens imóveis; criação e extinção de cargos públicos e fixação de vencimentos e vantagens; sistema tributário estadual, instituição de impostos, taxas, contribuições de melhoria e contribuição social.

Quanto às agências independentes, existem o Ministério Público, formalmente atrelado ao Executivo, ao qual compete exercer a fiscalização dos estabelecimentos prisionais e dos que abriguem idosos, menores, incapazes ou portadores de deficiências; deliberar sobre sua participação em organismos estatais de defesa do meio ambiente, do consumidor, de política penal e penitenciária e outros afetos a sua área de atuação; receber petições, reclamações, representações ou queixas de qualquer pessoa ou entidade representativa de classe, por desrespeito aos direitos assegurados na Constituição Federal e na Constituição Estadual; requisitar dos órgãos da administração direta ou indireta, os meios necessários a sua investigação; propor à autoridade administrativa competente a instauração de sindicância para a apuração de falta disciplinar ou ilícito administrativo.

Existe também o Tribunal de Contas do Estado, formalmente atrelado ao Legislativo, cujos conselheiros, vitalícios, são indicados da seguinte maneira:

1. dois, pelo Governador do Estado com aprovação da Assembléia Legislativa, alternadamente entre os substitutos de Conselheiros e membros da Procuradoria da Fazenda do Estado junto ao Tribunal, indicados por este, em lista tríplice, segundo critérios de antigüidade e merecimento;

2. quatro pela Assembléia Legislativa; 
3. o último, uma vez pelo Governador do Estado, e duas vezes pela Assembléia Legislativa, alternada e sucessivamente.

Ao Tribunal de Contas compete, no que se refere à Administração Estadual apreciar as contas prestadas anualmente pelo Governador do Estado, julgar as contas dos administradores e demais responsáveis por recursos públicos da administração direta e autarquias, empresas públicas e sociedades de economia mista; avaliar a legalidade dos atos de admissão de pessoal; avaliar a execução das metas previstas no plano plurianual, nas diretrizes orçamentárias e no orçamento anual; realizar inspeções e auditoria de natureza contábil, financeira, orçamentária, operacional e patrimonial, nas unidades administrativas dos Poderes Legislativo, Executivo e Judiciário, do Ministério Público; fiscalizar as aplicações estaduais em empresas de cujo capital social o Estado participe de forma direta ou indireta, nos termos do respectivo ato constitutivo; fiscalizar a aplicação de quaisquer recursos repassados ao Estado e pelo Estado, mediante convênio, acordo, ajuste ou outros instrumentos congêneres; aplicar aos responsáveis, em caso de ilegalidade de despesa ou irregularidade de contas, as sanções previstas em lei; assinar prazo para que o órgão ou entidade adote as providências necessárias ao exato cumprimento da lei, se verificada a ilegalidade; sustar, se não atendido, a execução do ato impugnado, comunicando a decisão à Assembléia Legislativa; representar ao Poder competente sobre irregularidades ou abusos apurados; comunicar à Assembléia Legislativa qualquer irregularidade verificada nas contas ou na gestão públicas, enviando-lhe cópia dos respectivos documentos.

Cabe-nos agora analisar o Legislativo para verificar a existência de jogadores com efetivo poder de veto. O Legislativo paulista é unicameral, exercido pela Assembléia Legislativa composta por noventa e quatro deputados.

Ferreira Costa e Oliveira (1998) analisaram a Assembléia Legislativa do Estado de São Paulo entre 1991 e 1994, e encontraram um parlamento fraco, tendo apontado como fatores internos à debilidade do Legislativo paulista a sua pouca visibilidade junto à população, organização arcaica e centralizadora do processo legislativo e baixa capacitação técnica, além de baixa informatização de rotinas, permitindo a manipulação do processo legislativo para acelerar ou retardar projetos de interesse da Mesa. Em março de 2000, seis anos após o período estudado pelos autores, a tramitação dos projetos, além de informatizada, foi 
totalmente disponibilizada para consulta de qualquer cidadão pela Internet. Entretanto, isso não significa que a Mesa tenha perdido os meios de manipulação do processo legislativo.

Em suas observações diretas sobre o funcionamento da Assembléia, verificaram que a composição proporcional das comissões (determinada pela Constituição Federal) reproduziria o amplo domínio do Executivo sobre a maioria da Assembléia, transformando o trabalho técnico das comissões em ficção, já que a aprovação ou não de um projeto de lei não dependeria do parecer das comissões, mas do interesse do Governador. A baixa qualificação dos quadros técnicos e o pouco interesse dos deputados em concentrar sua atuação parlamentar em alguma comissão permanente, contribuiriam para transformar as comissões em elemento secundário no processo decisório Legislativo. Como conseqüência, a atividade fiscalizadora da Assembléia seria quase nula, tendo como reflexo o pouco recurso às Comissões Parlamentares de Inquérito, não votação das contas prestadas por quatro Governadores (Maluf, Montoro, Quércia e Fleury - todas votadas no final de 1998, por força da aprovação da Emenda Constitucional n. ${ }^{\circ}$ 05, de 1998, após o período estudado pelos autores) e a difícil obtenção de informações dos parlamentares junto ao Tribunal de Contas do Estado e nas Secretarias estaduais.

Afirmam ainda que a arena de negociação entre o Executivo e o Legislativo não é pública em geral ocorre no Palácio dos Bandeirantes, sede do Poder Executivo e nas Secretarias de Estado, e à oposição só restaria obstruir o máximo possível o processo legislativo e investigar e denunciar possíveis irregularidades e erros políticos e administrativos do Executivo. Concluem que a baixa capacidade real de participação das decisões de governo é devida ao fato das decisões ocorrerem de forma individualizada e dispersa em diversos locais, mas não no Palácio Nove de Julho, sede do Poder Legislativo.

Apesar de citarem a centralidade do processo decisório dada por um Regimento Interno arcaico como um dos fatores de sua debilidade política, os autores não o analisaram, tampouco a Constituição estadual, no que se refere aos poderes legislativos do Governador e à real capacidade individual dos deputados de intervir no processo político, o que faremos a seguir.

A organização interna da Assembléia importa, para se verificar se há noventa e quatro jogadores com poder de veto efetivo ou não, e quem tem este poder. De acordo com o Regimento Interno, o Presidente é órgão da Assembléia, portanto analisaremos suas 
atribuições. Também analisaremos as competências do Plenário, da Mesa Diretora, das Comissões e dos Partidos Políticos.

Os membros da Mesa e seus substitutos devem ser eleitos para mandato de dois anos, presente a maioria dos membros da Assembléia, devendo ser assegurada, tanto quanto possível, a representação proporcional dos partidos políticos com assento na Assembléia Legislativa. À Mesa diretora compete dar posse aos Deputados, dar parecer em todas as matérias que versem sobre sua economia interna (sobre as quais tem iniciativa privativa) manifestar-se sobre qualquer matéria que vise alterar o Regimento interno, bem como decidir sobre o encaminhamento ao Governador do Estado de requerimentos de informações elaborados por deputados.

Ao Presidente compete zelar pela ordem nas sessões, responder soberanamente sobre qualquer questão de ordem (que são elaboradas por um deputado quando há dúvidas sobre a interpretação utilizada do regimento ou da Constituição pela Assembléia); determinar a pauta e proclamar o resultado das votações; não aceitar proposições anti-regimentais ou inconstitucionais (cabendo recurso à Comissão de Constituição e Justiça), determinar a publicação de matérias que devessem ser divulgadas, o não apanhamento de discurso antiregimental, pela taquigrafia; bem como autorizar (desde que sem ônus para a Assembléia) a transmissão dos trabalhos via rádio ou televisão; interromper o orador que fizer pronunciamento que contenha ofensa às instituições nacionais, propaganda de guerra, subversão da ordem política e social, preconceito de raça, religião ou classe, ou que configurasse crime contra a honra ou incitamento à prática de delito de qualquer natureza; designar relator especial para matérias com prazo vencido nas comissões; designar, mediante indicação dos líderes partidários, os membros das comissões; convocar sessões e a convocação extraordinária da Assembléia, de ofício ou mediante requerimento subscrito por um terço dos líderes da Assembléia.

Líder é o porta voz de uma representação partidária e o intermediário autorizado entre ela e os órgãos da Assembléia. No primeiro ano da legislatura, as representações partidárias devem indicar à Mesa, dentro de 10 dias do início da sessão legislativa, os respectivos Líderes e Vice-Líderes. Neste caso, enquanto não for feita a indicação, a Mesa considerará como Líder o deputado mais idoso da Bancada. Nos demais anos, as Bancadas poderão indicar os respectivos Líderes e Vice-Líderes a partir do início da sessão legislativa e até 15

CADERNOS GESTÃO PÚBLICA E CIDADANIA, V. 11, N. 48 - JAN/JUNHO 2006 
de março. Enquanto não for feita nova indicação, a Mesa considerará como Líder o atual e se, decorridos 10 dias desta data, não houver indicação, a Mesa passará a considerar como Líder o deputado mais idoso da Bancada.

Há, ainda, o Líder do Governo, indicado pelo Governador, com as mesmas disposições regimentais dos líderes das bancadas, apesar deste ser indicado pelo Chefe do Poder Executivo, ao contrário dos líderes partidários, indicados por seus companheiros de partido. Desta forma, o Líder do Governo é uma figura única na Assembléia: é representante de uma parcela da população paulista, eleito pelo sistema proporcional, portanto, também representante dos eleitores do partido do qual é membro e além disso, deve a sua posição de líder ao Chefe do Poder Executivo que o indicou pessoalmente, devendo atuar dentro do legislativo como seu representante.

Compete ao líder indicar o representante de sua bancada nas comissões e pronunciar-se durante a Ordem do Dia para encaminhamento de votações; participar, quando convocado das reuniões com o Presidente e demais líderes.

A representação proporcional dos Partidos, a qual se define com o número de lugares reservados aos Partidos em cada Comissão, é assegurada constitucionalmente. Na distribuição das vagas das Comissões Temporárias toma-se em conta as composições das Bancadas na data da aprovação dos respectivos requerimentos constitutivos e, nas Comissões Permanentes, cinco dias após o início da $1^{\mathrm{a}}$ sessão legislativa e, para o segundo biênio, em 15 de março, uma vez que os membros das Comissões Permanentes exercem suas funções até serem substituídos na $3^{\mathrm{a}}$ sessão legislativa da legislatura.

O parlamentar que deixar o Partido sob cuja legenda tenha sido efetuado o cálculo de proporcionalidade perde o cargo na Comissão Permanente ou Temporária. As modificações numéricas que ocorram nas Bancadas dos Partidos que importem modificações da proporcionalidade partidária na composição das Comissões só prevalecerão a partir da sessão legislativa subseqüente, salvo se o Partido deixar de ter representante na Assembléia, caso em que a Mesa deve providenciar imediatamente a redistribuição das vagas.

Ao Presidente da Comissão compete: convocar e estabelecer a pauta das reuniões, designar relatores e o seu prazo para análise de proposições, requerer ao Presidente da Assembléia o desligamento de Deputado que tenha faltado consecutivamente e sem justificativa a mais de cinco reuniões ordinárias, responder às questões de ordem suscitadas no âmbito de sua 
comissão, cabendo recurso ao Presidente da Assembléia e autorizar a divulgação de informações das comissões a pessoas estranhas à Assembléia.

Verifica-se que as Comissões têm diversas atribuições, entretanto, o seu Presidente tem poder para estabelecer sua agenda. Os presidentes das Comissões teriam efetivo poder de veto se não existisse a figura do Relator Especial, qualquer deputado, designado pelo Presidente, para atuar em substituição à comissão. Vários projetos podem ir a plenário sem serem deliberados pelas comissões. Um projeto do Governador com pedido de urgência constitucional pode ser analisado somente por deputados da confiança do Presidente, antes de chegarem ao Plenário. Em plenário, quem determina a pauta, é o Presidente. Caso o regimento ou a Constituição sejam desrespeitados, cabe ao Presidente decidir se a votação foi válida ou não. Portanto, no Legislativo paulista, há um jogador com efetivo poder de veto, o seu Presidente.

Como são eleições simultâneas e devido aos recursos do Executivo todos controlados pelo Governador, não deve ser difícil para o Governador conseguir eleger um aliado como Presidente, especialmente se a Constituição federal determina que a Mesa Diretora deve respeitar a proporcionalidade partidária.

Desta forma, o que se poderia esperar da legislação eleitoral e partidária, incentivando inúmeros jogadores com poder de veto, não se verifica ao se olhar para um nível mais detalhado, dentro do legislativo. Dificilmente em um sistema político como esse haveria impasse ou bloqueio decisório, mas pode haver uma sub-representação da heterogeneidade da sociedade.

Agora, com base no Institucionalismo Histórico, procuraremos ver a gênese dessas regras internas ao processo decisório no interior do Legislativo. A Assembléia Legislativa do Estado de São Paulo considera-se em sua $16^{\text {a }}$ Legislatura, poder-se-ia pesquisar nos regimentos e constituições (instituições formais e públicas da Assembléia) a partir de 1947, data de início da Primeira Legislatura. Porém, nas regras para discussão do Regimento Interno da Assembléia Constituinte de 1947 (Resolução n. ${ }^{\circ}$ 10, de 1947), faz-se referência ao Regimento utilizado pela Assembléia fechada em 1937, para o caso de dirimir dúvidas e situações não previstas naquela Resolução. O Regimento utilizado em 1935, da mesma forma, remetia para o Regimento da Câmara dos Deputados estadual fechada em 1930. 
Diante destas claras ligações retrospectivas, e da afirmação dos institucionalistas de que as escolhas passadas restringem as opções futuras (PUTNAM 1996), preferiu-se consultar os regimentos e constituições disponíveis desde a instalação da Assembléia Legislativa Provincial, em 1835, a fim de identificar as origens dos mecanismos presentes no sistema decisório atual.

Verificou-se que no regimento em vigor, existem dispositivos do Império, da Primeira República e da Assembléia fechada pelo Estado Novo. Porém, as principais características do Regimento em vigor são de 1956, apesar da Constituição ter sido reformada em 1965, 1974, 1980, 1982, 1984 e 1989 e estas mudanças terem repercutido, em maior ou menor grau, no Regimento Interno vigente. A centralização de Poderes nas mãos do Presidente e a ausência de estímulos à participação ativa dos deputados data de 1956, uma reforma autóctone, desvinculada de reformas constitucionais.

Em um primeiro momento, pode parecer estranha e extemporânea a reforma regimental ocorrida em 1956. O contexto constitucional estadual e federal não se havia alterado, o número de membros da Assembléia somente cresceu na legislatura seguinte, e o Governador (Jânio da Silva Quadros), era relativamente novo na política estadual, apesar de já haver sido prefeito da Capital e deputado estadual (durante a segunda legislatura). PUTNAM (1996) afirma que o fortalecimento das instituições deve ser medido em décadas, não se restringindo ao momento de elaboração da carta constitucional. Em 1947, um parlamento novo deparou-se com um Executivo forte, com funcionários estáveis. A Assembléia não existiu por aproximadamente dez anos, mas a Administração estadual sim, e neste meio tempo foi criada uma burocracia estável na administração e o raio de atuação estatal foi ampliado. Aos deputados destas primeiras legislaturas competia criar um parlamento e torná-lo atuante.

CAMPELLO DE SOUZA (1976) afirma que tanto a Primeira República quanto o Estado Novo são sistemas elitistas, apesar de se basearem em sistemas diversos: a Primeira República baseava-se na autonomia estadual e na política dos Governadores, e o Estado Novo na unificação mediante a intervenção nos estados e a implantação de uma ampla rede de órgãos burocráticos, ao mesmo tempo em que suspendeu o funcionamento das organizações partidárias. Na ausência dos canais tradicionais de influência e representação, as oligarquias estaduais foram redirecionadas para um sistema de interventorias e 
departamentos administrativos que as interligava aos Ministérios e à Presidência da República. A autora afirma ainda que as mudanças político-institucionais iniciadas pela Revolução de 1930 resultaram na criação de uma extensa máquina burocrática não controlada por um legislativo ou qualquer outro organismo de representação da sociedade.

Em 1946 não houve o desmantelamento total do Estado Novo, como também não se pode afirmar que tenha havido total continuidade, mas o sistema de predomínio do Executivo, bem como a centralização dos poderes foram mantidos. O primeiro Governador eleito, em 1947, Ademar de Barros (1947 a 1951 e 1963 a 1966), já havia sido interventor durante o Estado Novo (1938 a 1941). Além de toda a tradição burocrática dos dezessete anos anteriores, o legislativo novato se deparou não só com uma Administração experiente, mas com o Chefe do Poder Executivo também experiente e não acostumado a qualquer contrapeso de poder.

Quando reaberta em 1935, a Assembléia em seu regimento já previa uma centralização de poder nas mãos do seu Presidente: a faculdade de decidir soberanamente sobre as questões de ordem, o que lhe dava grande margem de arbítrio. Na sua nova reabertura, em 1947, mais poderes foram concentrados nas mãos do Presidente e dos líderes partidários, dentre as quais a nomeação, pelo presidente, dos membros das comissões mediante indicação do líder partidário, bem como a triagem de proposições, substituindo a primeira discussão em plenário. A criação do relator especial, em 1951, de livre nomeação do Presidente para manifestar-se em substituição a uma comissão ampliou ainda mais o arbítrio do Presidente da Assembléia.

Em 1956, a reforma do regimento centralizou ainda mais os poderes nas mãos do Presidente da Assembléia, e dos líderes partidários, em detrimento dos deputados e das comissões. Além disso, parte do tempo destinado a deliberação foi transformado em tempo usado pelos deputados para versarem de assuntos de sua livre escolha na tribuna, e as sanções ao não comparecimento dos deputados foram bastante reduzidas, comprometendo a participação ativa da Assembléia no processo de governo estadual. Deve-se salientar que esta reforma praticamente extinguiu as sanções para o não cumprimento do Regimento, transformando-o em mera referência, não regra a ser seguida para a tomada de decisões. Porém, esta reforma foi aprovada pela maioria dos membros da Assembléia. 
A hipótese que pode ser levantada para explicar este ‘suicídio institucional' cometido em 1956 pelos deputados paulistas é que a Assembléia por quase dez anos tentou, sem sucesso, impor-se como poder autônomo e ócus das decisões governamentais do estado. Porém, o arranjo institucional vigente até 1956 apenas onerava os seus membros, pois exigia a presença de seus membros no Palácio Nove de Julho, reduzindo, assim, o tempo de que estes dispunham para atuar onde poderiam conseguir maiores resultados para as suas carreiras políticas, isto é, junto às bases e nos órgãos da administração estadual, e não lhes oferecia espaço para divulgar suas idéias (Pequeno e Grande Expediente e Explicação Pessoal).

A Resolução 576, de 1970, afirma em sua ementa que se dispõe a adequar o Regimento Interno da Assembléia às normas constitucionais vigentes. A Constituição em vigor em 1970 havia sido alterada de acordo com a Constituição federal reformada, ou seja, as alterações ocorridas em 1970 no Regimento Interno não foram determinadas pelos deputados, contrariamente ao que ocorreu em 1956, onde o Regimento foi bastante alterado com relação ao anterior, pela vontade dos deputados membros da Assembléia àquele momento.

Entre 1970 e 1982, a Assembléia era um parlamento de fachada, sem qualquer poder. Porém, muitas das suas restrições eram constitucionais, das quais grande parte foi revogada, e, conseqüentemente, também o foram algumas disposições constantes da Resolução n. ${ }^{\circ}$ 576, de 1970 (apesar de outras ainda subsistirem sem obrigatoriedade constitucional).

De 1930 a 1970 as atribuições do Poder Legislativo paulista foram se reduzindo. A Constituição de 1989, apesar de ampliar as atribuições do legislativo, acolheu muitas das disposições da Constituição anterior, principalmente no que se refere aos poderes legislativos do Governador, correspondente ao que ocorreu no nível federal, conforme apontado por FIGUEIREDO e LIMONGI (1999). As principais atribuições adquiridas pela Assembléia paulista, em 1989, referem-se principalmente à sua função fiscalizatória, porém a estrutura decisória interna da Assembléia, que concentra o poder nas mãos da Mesa Diretora, em especial, de seu Presidente, as inviabiliza. A alteração desta estrutura não depende de fatores externos, mas internos ao Legislativo paulista. Porém, dificilmente poderá ser modificada, uma vez que qualquer democratização do sistema decisório depende 
de parecer da Mesa Diretora que é quem mais tem a perder com qualquer alteração regimental.

O atual sistema decisório da Assembléia inviabiliza a atuação parlamentar nas suas prerrogativas constitucionais. Desde 1956, as principais atividades exercidas pelos deputados estaduais paulistas devem ser desenvolvidas em áreas e formas não previstas na Constituição e no Regimento Interno, portanto em uma arena não pública (ainda que estatal), possivelmente como lobbistas nas agências do Executivo, de forma não documentada, de difícil quantificação e qualificação, passando a imagem de um parlamento inoperante e fraco, frente aos demais poderes.

Pode-se argumentar que a Mesa Diretora é eleita pelos deputados membros da Assembléia, portanto, quando e se houver vontade política, os deputados poderão eleger uma Mesa disposta a democratizar o sistema decisório da Assembléia. Porém, a Constituição paulista de 1989, a exemplo da Constituição federal de 1988, estabelece que a composição da Mesa Diretora deve observar a proporcionalidade dos partidos com assento na Casa Legislativa. Isto significa que o ócus da escolha da Mesa Diretora é o partido, não a Casa Legislativa, e, tendo sido escolhido ou indicado pelo partido, abrir mão de poder não traria nenhum benefício político aos partidos ou aos membros da Mesa Diretora.

Respeitadas as suas diferentes atribuições e competências, verifica-se que, comparativamente, o Presidente da República dispõe de maiores poderes legislativos que o Governador do Estado de São Paulo (urgência urgentíssima e medidas provisórias) na atual ordem constitucional, e os deputados paulistas dispõem de maiores prerrogativas de atuação que os deputados federais e senadores (para a fiscalização do Estado). Porém, o legislativo federal é muito mais atuante nas questões de governo que o legislativo estadual paulista, que não está organizado internamente para intervir de forma institucional no sistema político paulista e, portanto, é incapaz de utilizar as suas prerrogativas.

Diferentemente da Câmara de Deputados descrita por FIGUEIREDO e LIMONGI (1999), na qual os recursos legislativos estão concentrados nas mãos dos membros da Mesa Diretora e dos líderes partidários, na Assembléia paulista, os recursos estão em grande parte nas mãos de seu Presidente, que tem poderes quase absolutistas, uma vez que concentra poderes executivos, legislativos e judiciários dentro da Assembléia.

CADERNOS GESTÃO PÚBLICA E CIDADANIA, V. 11, N. 48 - JAN/JUNHO 2006 
Muitos dos parlamentares, desde 1956, têm o papel de figurantes na Assembléia, principalmente se não forem membros da Mesa Diretora, Líderes e, em alguns casos, Presidentes de Comissões (as relatorias especiais, bem como a difícil punição pela ausência nas reuniões podem facilmente tornar uma comissão inoperante, a despeito da vontade de seu presidente). O sistema decisório centralizado em vigor solapa toda a representatividade do legislativo paulista e impede que as minorias tenham voz, ainda que tenham conseguido eleger seu representante.

Entretanto, a correspondência entre a centralidade decisória e a preponderância legislativa do Executivo não é automática: há momentos de centralização decisória na Assembléia (1956) sem que os poderes legislativos do Executivo tivessem sido aumentados, e uma redução dos poderes legislativos do Chefe do Poder Executivo, sem uma descentralização do processo decisório da Assembléia (1989).

WEBER (1974) afirma que o nível do parlamento depende de sua importância em influenciar questões efetivamente importantes e somente em um parlamento ativo pode haver terreno para o crescimento e a ascensão seletiva de líderes genuínos e não meros talentos demagógicos. A supervisão contínua introduzida pelo direito de inquérito parlamentar é pré-condição básica para todas as reformas posteriores que objetivam a ampliação da participação do parlamento no governo, indispensável para fazer do parlamento um centro de recrutamento de líderes. Porém, a demagogia ignorante ou a impotência rotinizada triunfam em um parlamento que não tem acesso aos fatos e cujos líderes nunca são colocados em situações nas quais tenham que mostrar seu valor.

WEBER referia-se à Alemanha de Bismarck, mas se os membros se adaptam ao parlamento e vice-versa (OLSON 1994), os parlamentares causaram um grande dano, em 1956, com a reforma do Regimento Interno da Assembléia paulista, que inviabiliza a influência da maioria dos deputados sobre as questões mais relevantes do Estado, o que os torna jogadores sem poder de veto efetivo, desde então, garantindo a decisibilidade do Estado, apesar da Legislação eleitoral e partidária promover a sua resolutividade.

Não se pode creditar a centralidade decisória e os estímulos institucionais à não participação ativa dos deputados no âmbito do parlamento, onde as decisões e as negociações são públicas, ao regime autoritário em vigor no país em 1970, quando da 
publicação da Resolução n. ${ }^{\circ}$ 576, de 1970, mas aos próprios deputados que elaboraram e que mantiveram a estrutura criada em 1956, pela Resolução n. ${ }^{\circ} 207$.

Um olhar para o passado e a escolha de instituições mais detalhadas (em um nível meso) pode facilitar a compreensão do comportamento dos atores em um dado momento. Restringir-se às instituições macro, no caso do presente estudo, poderia nos levar à conclusão errada, de que haveria diversos atores com poderes de veto no sistema político do Estado de São Paulo, o que não se confirmou e agora sabemos desde quando, 1956, em pleno regime democrático.

Roberta Clemente é mestre e doutoranda em Administração Pública e Governo pela EAESP/FGV e Agente Técnico Legislativo na Assembléia Legislativa Paulista.

\section{Referências Bibliográficas}

ABRUCIO, Fernando Luiz. Os Barões da Federação: os governadores e a redemocratização brasileira. São Paulo: Hucitec/Departamento de Ciência Política, USP, 1998a

ABRUCIO, Fernando Luiz. O Ultrapresidencialismo Estadual. In ANDRADE, Regis de Castro (org.). Processo de Governo no Município e no Estado. São Paulo: Editora da Universidade de São Paulo, 1998b

ANDRADE, Regis de Castro (org.). Processo de Governo no Município e no Estado. São Paulo: Editora da Universidade de São Paulo, 1998

CAMPELLO DE SOUZA, Maria do Carmo. Estado e Partidos Políticos no Brasil (1930 a 1964). São Paulo: Alfa-Omega, 1976.

CLEMENTE, Roberta. A Evolução Histórica das Regras do Jogo Parlamentar em uma Casa Legislativa: O Caso da Assembléia Legislativa do Estado de São Paulo. Dissertação apresentada ao Curso de Pós-Graduação da FGV/EAESP. São Paulo, 2000.

FERREIRA COSTA, Valeriano Mendes e OLIVEIRA, Carlos Thadeu C. de. A Fraqueza da Assembléia Legislativa do Estado de São Paulo. In ANDRADE, Regis de Castro (org.). "Processo de Governo no Município e no Estado". São Paulo: Editora da Universidade de São Paulo, 1998

FIGUEIREDO, Argelina Cheibub e LIMONGI, Fernando. Executivo e Legislativo na nova ordem constitucional. Rio de Janeiro: Editora FGV. 1999

HAGGARD, Stephan \& McCUBBINS, Matthew. Presidents, Parliaments and Policy. Cambridge University Press. 2001 
HUBER, John D. Restrictive Legislative Procedures in France and the United States.American Political Science Review Vol. 86, No. 3 September 1992, pp. 675 - 687.

LIMA JÚNIOR, Olavo Brasil de. Instituições Políticas Democráticas: o Segredo da Legitimidade. Rio de Janeiro: Jorge Zahar Ed., 1997

O’DONNEL, Guillermo. Poliarquias e a (In)Efetividade da Lei na América Latina. Novos Estudos CEBRAP n. ${ }^{\circ}$ 51, Julho de 1998 pp37 - 62.

OLIVEIRA, Francisco. A Crise da Federação: da oligarquia à Globalização. In: AFFONSO, Rui de Brito Álvares, SILVA, Pedro Luiz Barros. A Federação em Perspectiva: Ensaios Selecionados. - São Paulo: FUNDAP, 1995

OLSON, David M. Democratic Legislative Institutions: a comparative view. Armonk, NY: ME Sharpe Inc.: 1994

PUTNAM, Robert D., LEONARDI, Robert e NANETTI, Raffaella Y. Comunidade e Democracia: a experiência da Itália moderna. Rio de Janeiro: Editora Fundação Getulio Vargas, 1996.

ROSENTHAL, A. (1998) "The Decline of Representative Democracy: process, participation and Power in State Legislatures.” Washington DC: Congressional Quarterly Inc.

SANTOS, Fabiano G. M. Microfundamentos do Clientelismo Político no Brasil: 1959 1963. Dados - Revista de Ciências Sociais, Rio de Janeiro, Vol. 38, n. 3, 1995, pp. 459 a 496.

STEPAN, Alfred. Toward a New Comparative Analysis of Democracy and Federalism: Demos Constraining and Demos Enabling Federations. Paper apresentado ao Meeting of the International Political Science Association. 1997 (mimeo).

THELEN, Katherine. Historical Institutionalism in Comparative Politics. Review of Political Science, 1999, 2 pp. 369-404.

WEBER, Max. Parlamentarismo e Governo numa Alemanha Reconstruída (uma contribuição à crítica da política do funcionalismo e da política partidária). São Paulo: Abril Cultural, 1974 (Coleção Os Pensadores XXXVII).

Artigo recebido em 22/09/2005 e aprovado em 20 /11/2005 